\title{
Determination of flow-rate characteristics and parameters of piezo pilot valves
}

\author{
Jakub Takosoglu ${ }^{1, *}$, Pawet Laski ${ }^{2}$, Slawomir Blasiak ${ }^{1}$, Gabriel Bracha ${ }^{2}$, Dawid Pietrala ${ }^{2}$, Jaroslaw Zwierzchowski ${ }^{2}$, \\ Lukas Nowakowski ${ }^{1}$ \\ ${ }^{1}$ Faculty of Mechatronics and Mechanical Engineering, Department of Manufacturing Engineering and Metrology, Kielce University of \\ Technology, Aleja Tysiaclecia Panstwa Polskiego 7, 25-314 Kielce, Poland \\ ${ }^{2}$ Faculty of Mechatronics and Mechanical Engineering, Department of Automation and Robotics, Kielce University of Technology, Aleja \\ Tysiaclecia Panstwa Polskiego 7, 25-314 Kielce, Poland
}

\begin{abstract}
Pneumatic directional valves are used in most industrial pneumatic systems. Most of them are two-stage valves controlled by a pilot valve. Pilot valves are often chosen randomly. Experimental studies in order to determine the flow-rate characteristics and parameters of pilot valves were not conducted. The paper presents experimental research of two piezo pilot valves.
\end{abstract}

\section{Introduction}

Pneumatically driven devices are used almost in every industry (medical, transport, aviation [1-4], automotive, light and heavy industries, mining, metallurgy, CNC [59], robotics [10-16]) as well as in our everyday lives [1720]. In order to control pneumatic drives, mainly pneumatic directional valves are used [21, 22], which can be: mechanically, manually, pneumatically and electro-magnetically operated. Due to the dynamic development of electronics [23] and programmable controlling [24, 25], production processes mainly use PLCs [26, 27]. Hence, pneumatic directional valves electromagnetically operated are widely applied in the pneumatic devices. Pneumatic directional valves are built of two primary components:

- pneumatic distributor, which is responsible for the subsequent stage (action) of the valve,

- $\quad$ pilot valve(s), which is responsible for the initial stage (action) of the valve [28].

The pilot valves of the directional valves are usually selected randomly. Catalogues of companies of the pneumatic industry do not include the parameters of pilot valves as such, only parameters of a complete set - the distributor and the pilot valve constituting the directional valve. Two piezo pilots [29-31] by Hoerbiger-Origa: P20 381RF-NG-CPN (Fig. 1) and P8 385RF-NG-SPN61-B (Fig. 2) are the subject of the research. The parameters thereof are shown in Table 1 and Table 2 respectively. Those elements were selected for research due to the possibility to compare the data provided by the producer in the catalogue with the results obtained.
Table 1. Parameters of P20 381RF-NG-CPN pilot valve.

\begin{tabular}{|l|c|}
\hline \multicolumn{1}{|c|}{ Parameters } & Value \\
\hline Nominal size & $2 \mathrm{~mm}$ \\
\hline Valve function & 3/2-way, normally closed \\
\hline Nominal pressure & $0.6 \mathrm{MPa}$ \\
\hline Operating pressure range & $0.12-0.8 \mathrm{MPa}$ \\
\hline Critical pressure ratio $b$ & 0.33 \\
\hline Sonic conductance $C$ & $4.42 \cdot 10^{-9} \mathrm{~m}^{3} /(\mathrm{s} \cdot \mathrm{Pa})$ \\
\hline Nominal flow rate & $18.33 \cdot 10^{-4} \mathrm{~m}^{3} / \mathrm{s}$ \\
\hline
\end{tabular}

a) b)
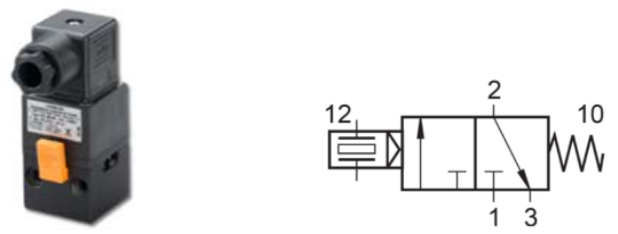

Fig. 1. P20 381RF-NG-CPN: a) general view, b) symbol

Table 2. Parameters of P8 385RF-NG-SPN61-B pilot valve.

\begin{tabular}{|l|c|}
\hline \multicolumn{1}{|c|}{ Parameters } & Value \\
\hline Nominal size & $1.6 \mathrm{~mm}$ \\
\hline Valve function & $3 / 2$-way, normally closed \\
\hline Nominal pressure & $0.6 \mathrm{MPa}$ \\
\hline Operating pressure range & $0.12-0.8 \mathrm{MPa}$ \\
\hline Critical pressure ratio $b$ & 0.34 \\
\hline Sonic conductance $C$ & $2.08 \cdot 10^{-9} \mathrm{~m}^{3} /(\mathrm{s} \cdot \mathrm{Pa})$ \\
\hline Nominal flow rate & $8.33 \cdot 10^{-4} \mathrm{~m}^{3} / \mathrm{s}$ \\
\hline
\end{tabular}

a)

b)
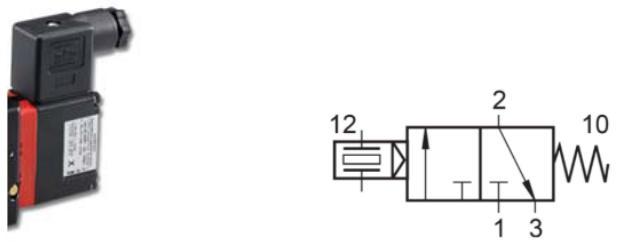

Fig. 2. P8 385RF-NG-SPN61-B: a) general view, b) symbol 


\section{Flow parameters}

Pneumatic systems via working medium, most often compressed air, host the exchange of energy and control signals [32-35]. Pneumatic devices are characterized by resistance [36-38], which influences the flow rate of the compressed air, and hence, its flow intensity. Those characteristics are described by flow parameters, which can be determined on the basis of experiments [39-41]. The method of studying pneumatic components that host the exchange of compressible gases is described by ISO 6358 [42].

\subsection{Choked flow}

Critical flow is a state, in which the gas flow rate in a certain area of the component equals the local speed of sound. It occurs when inlet pressure $p_{l}$ is high enough in relation to outlet pressure $p_{2}$. Massive gas flow intensity is then proportional to inlet pressure $p_{l}$ and inversely proportional to the square root of the temperature at inlet $T_{1}$, and does not depend on outlet pressure $p_{2}$ :

$$
\begin{gathered}
q_{m}^{*}=C \cdot p_{1} \cdot \rho_{0} \sqrt{\frac{T_{0}}{T_{1}}} \text { for } \frac{p_{2}}{p_{1}} \leq b \\
q_{m}=C \cdot p_{1} \cdot \rho_{0} \sqrt{\frac{T_{0}}{T_{1}}} \sqrt{1-\left(\frac{\frac{p_{2}}{p_{1}}-b}{1-b}\right)^{2}} \text { for } \frac{p_{2}}{p_{1}}>b
\end{gathered}
$$

where:

$q_{m}{ }^{*}$ - mass flow intensity under choked flow conditions,

$q_{m}$ - mass flow intensity under subsonic flow,

$p_{l}-$ inlet gas pressure,

$p_{2}$ - outlet gas pressure,

$\rho_{0}$ - gas density,

$C$ - sonic conductance,

$b$ - critical pressure ratio,

$T_{0}$ - normalized reference temperature,

$T_{1}-$ inlet temperature.

\subsection{Critical pressure ratio}

Critical pressure ratio $b$ is the highest value of $\mathrm{p}_{2} / p_{1}$ pressure ratio, which triggers choked flow in the tested component [42]. If the inlet temperature is constant during research, then value $b$ for each obtained value $q_{m}$ in terms of subsonic flow [43, 44] is calculated using the formula presented below:

$$
b=1-\frac{\frac{\Delta p}{p_{1}}}{1-\sqrt{1-\left(\frac{q_{m}}{q_{m}^{*}}\right)^{2}}}
$$

where:

$\Delta p$ - pressure drop.

If during the research, a change in $p_{I}$ and $T_{1}$, occurs, then for each value $q_{m}$ received in terms of subcritical flow, $b$ is calculated on the basis of the following formula:

$$
b=1-\frac{\frac{\Delta p}{p_{1}}}{1-\sqrt{1-\left(\frac{q_{m}}{C \rho_{0} p_{1}} \sqrt{\frac{T_{1}}{T_{0}}}\right)^{2}}}
$$

\subsection{Sonic conductance}

Sonic conductance $C$ is the ratio of mass gas flow intensity $q_{m}{ }^{*}$ through the component, to the product of inlet pressure $p_{1}{ }^{*}$ and the density of that gas $\rho_{0}$ in normalized reference atmosphere conditions during choked flow:

$$
C=\frac{q_{m}^{*}}{p_{1}^{*} \cdot \rho_{0}} \sqrt{\frac{T_{1}^{*}}{T_{0}}}
$$

where:

$p_{1}{ }^{*}-$ inlet gas pressure under choked flow conditions,

$T_{1}{ }^{*}$ - inlet temperature under choked flow conditions.

The symbols and units shall be applied in accordance with Table 3. The numerals used in subscripts or superscripts or marked with an asterisk $(*)$ with regard to the symbols listed in Table 2 shall be used as specified in Table 4.

Table 3. Symbols and units.

\begin{tabular}{|l|c|c|}
\hline \multicolumn{1}{|c|}{ Description } & Symbol & SI unit \\
\hline Critical pressure ratio & $b$ & - \\
\hline Sonic conductance & $C$ & $\mathrm{~m}^{3} /(\mathrm{s} \cdot \mathrm{Pa})$ \\
\hline Absolute stagnation pressure & $p$ & $\mathrm{~Pa}$ \\
\hline Mass flow rate & $q_{m}$ & $\mathrm{~kg} / \mathrm{s}$ \\
\hline $\begin{array}{l}\text { Volume flow rate at standard } \\
\text { reference atmosphere }\end{array}$ & $q_{v}$ & $\mathrm{~m}^{3} / \mathrm{s}(\mathrm{ANR})$ \\
\hline Gas constant (for a perfect gas) & $R$ & $\mathrm{~J} /(\mathrm{kg} \cdot \mathrm{K})$ \\
\hline $\begin{array}{l}\text { Absolute stagnation } \\
\text { temperature }\end{array}$ & $T$ & $\mathrm{~K}$ \\
\hline Mass density & $\rho$ & $\mathrm{kg} / \mathrm{m}^{3}$ \\
\hline
\end{tabular}

Table 4. Subscripts and superscripts.

\begin{tabular}{|c|c|l|}
\hline Superscript & Subscript & \multicolumn{1}{|c|}{ Meaning } \\
\hline & 0 & $\begin{array}{l}\text { Conditions of standard } \\
\text { reference atmosphere defined }\end{array}$ \\
& & in ISO 8778, i.e.: \\
& & $T_{0}=293.15 \mathrm{~K}$ \\
& & $p_{0}=0.1 \mathrm{MPa}$ \\
& & $\rho_{0}=1.185 \mathrm{~kg} / \mathrm{m}^{3}$ \\
& & $65 \%$ relative humidity RH \\
\hline & 1 & Upstream conditions \\
\hline & 2 & Downstream conditions \\
\hline$*$ & & Conditions during choked \\
& & flow tests \\
\hline
\end{tabular}

If a volumetric flow meter was used for the measurements, and the volumetric flow intensity is to be used, then the formulae (1), (2), (3), (4), (5) will take the following form:

$$
\begin{gathered}
q_{m}=\rho \cdot q_{v} \\
b=1-\frac{\frac{\Delta p}{p_{1}}}{1-\sqrt{1-\left(\frac{q_{v}}{q_{v}^{*}}\right)^{2}}} \\
b=1-\frac{\frac{\Delta p}{p_{1}}}{1-\sqrt{1-\left(\frac{q_{v}}{C p_{1}} \sqrt{\frac{T_{1}}{T_{0}}}\right)^{2}}}
\end{gathered}
$$




$$
C=\frac{q_{v}^{*}}{p_{1}^{*}} \sqrt{\frac{T_{1}^{*}}{T_{0}}}
$$

\section{Test stand}

The test stand used to determine the flow rate characteristics of piezo pilot valves is shown in Fig. 3, whereas the overview of the stand in Fig.4.

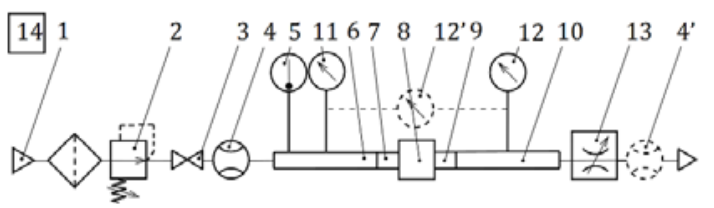

Fig. 3. The diagram of the test stand applied to determine the flow rate characteristics: 1 - compressed gas source and filter, 2 - adjustable pressure regulator, 3 - shut-off valve, 4 - flowrate measuring device, 5 - temperature-measuring instrument, 6 - upstream pressure-measuring tube, 7 - upstream transition connector, 8 - component under test, 9 - downstream transition connection, 10 - downstream pressure-measuring tube, 11 upstream pressure gauge or transducer, 12 - downstream pressure gauge or transducer, 13 - flow control valve, 14 barometer.

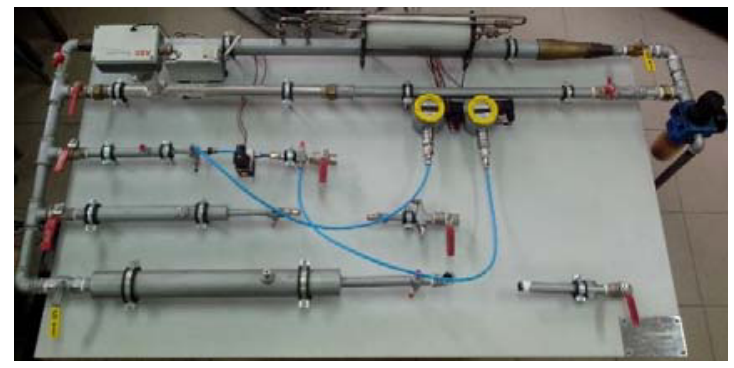

Fig. 4. General view of the test stand

Flow characteristic $p_{2}=f(q)$ of the component is the dependency of the overpressure behind component $p_{2}$, in the flow function of volume or weight $q$, under constant overpressure in front of component $p_{l}$. Company catalogues present it in a graphical form, primarily with $p_{l}=0.6 \mathrm{MPa}$ or $p_{I}=0.63 \mathrm{MPa}$. Such characteristic can be obtained by maintaining constant overpressure in front of the component with the use of a reducing valve and changing the flow behind the component with the use of a ball valve. The individual characteristic is presented also as the dependency of pressure drop $\Delta p=p_{1}-p_{2}$ in component $\Delta p=f(q)$. Other characteristics are also common, such as $p_{2} / p_{1}=f(q)$ and $q=f\left(p_{2} / p_{1}\right)$. The family of the ordinary flow-rate characteristics is comprised of characteristics $p_{2}=f\left(q, p_{1}\right)$ obtained under different constant values of overpressure $p_{1}$ in front of the component. These values are usually taken from a standardized chain: $0.16 ; 0.25 ; 0.4 ; 0.63 ; 0.8 ; 1.0 ; 1.2$ $\mathrm{MPa}$. The family of the characteristics is also presented in $\Delta p \%=f\left(q, p_{1}\right)$, where $\Delta p \%=\left(\left(p_{1}-p_{2}\right) / p_{1}\right) \cdot 100 \%$. Similarly to the individual characteristic, the families of the ordinary characteristics are shown graphically as well.

\section{Experimental research results}

The experimental research was conducted under constant inlet pressure $p_{I}=$ const and constant temperature $T_{0}=T_{1}=$ const. Fig. 5 and 6 show a graphical interpretation [45] of the results of the experimental research on piezo pilot valves concerning the determination of critical pressure ratio $b$ and sonic conductance $C$. The charts in Fig.7-10 show different flow rate characteristics of the pilots. The charts in Fig. 11-12 present characteristics $C=f\left(p_{2} / p_{1}\right)$ of sonic conductance $C$ in the function of pressure ratio $p_{2} / p_{1}$.

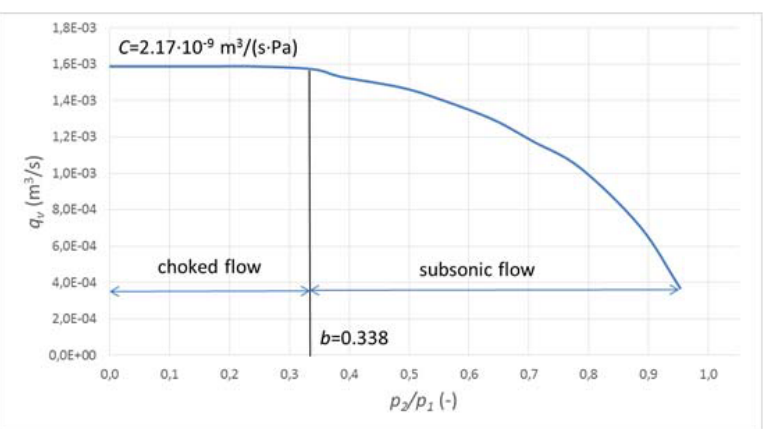

Fig. 5. Graphical interpretation of critical pressure ratio $b$ and sonic conductance $C$ of P8 385RF-NG-SPN61-B pilot.

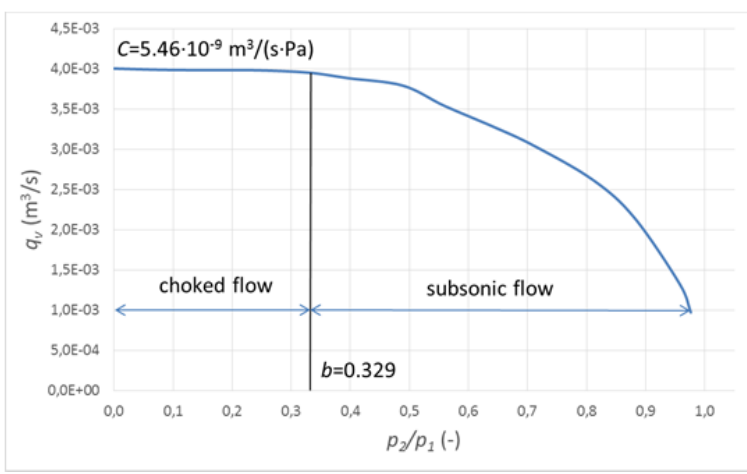

Fig. 6. Graphical interpretation of critical pressure ratio $b$ and sonic conductance $C$ of P20 381RF-NG-CPN pilot.

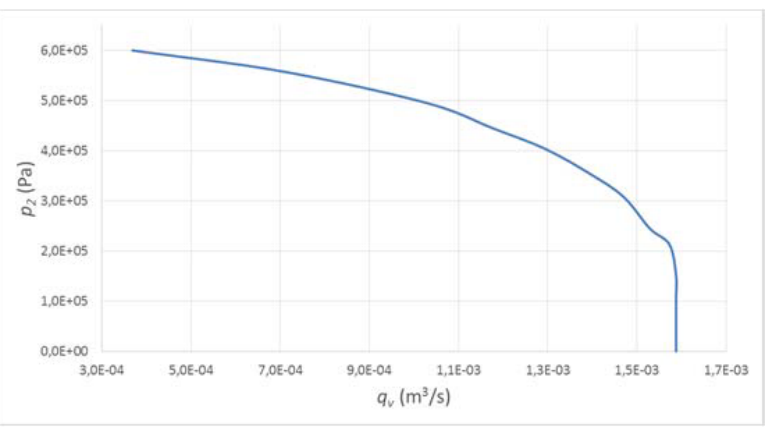

Fig. 7. Flow-rate characteristic $p_{2}=f\left(q_{v}\right)$ of $\mathrm{P} 8385 \mathrm{RF}-\mathrm{NG}-$ SPN61-B pilot. 


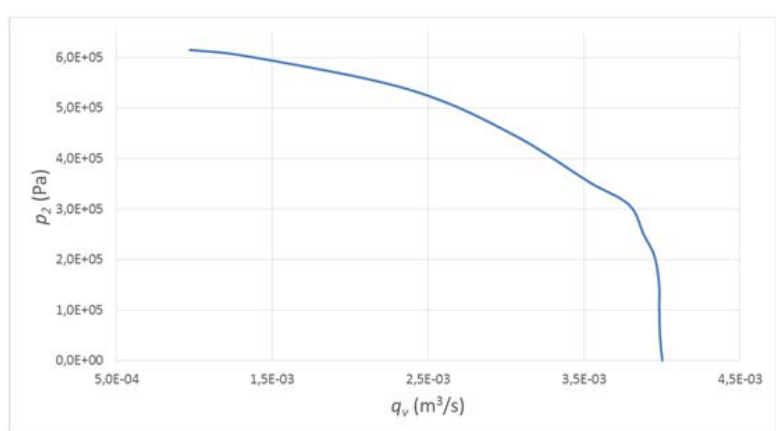

Fig. 8. Flow-rate characteristic $p_{2}=f\left(q_{v}\right)$ of P20 381RF-NGCPN pilot.

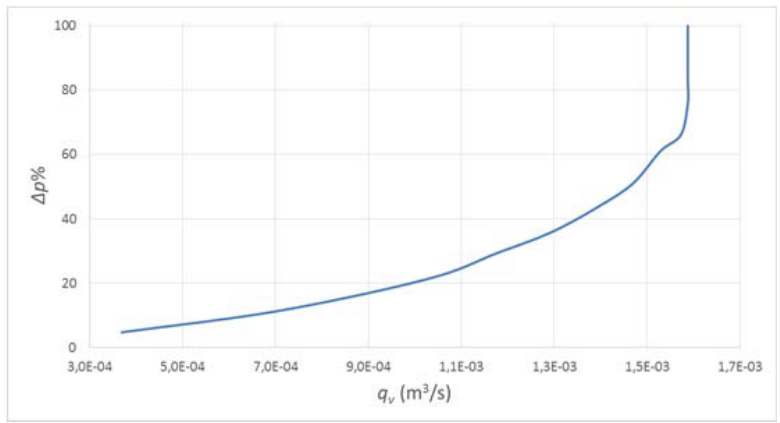

Fig. 9. Flow-rate characteristic $\Delta p \%=f\left(q_{v}\right)$ of $\mathrm{P} 8385 \mathrm{RF}-\mathrm{NG}-$ SPN61-B pilot.

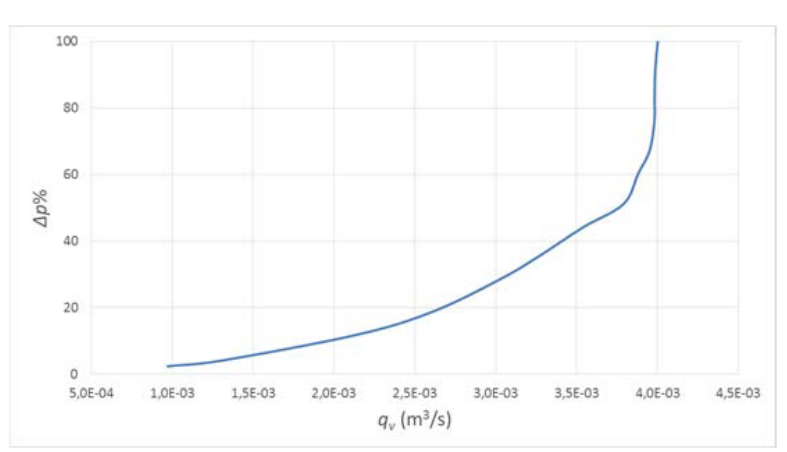

Fig. 10. Flow-rate characteristic $\Delta p \%=f\left(q_{v}\right)$ of P20 381RF-NGCPN pilot.

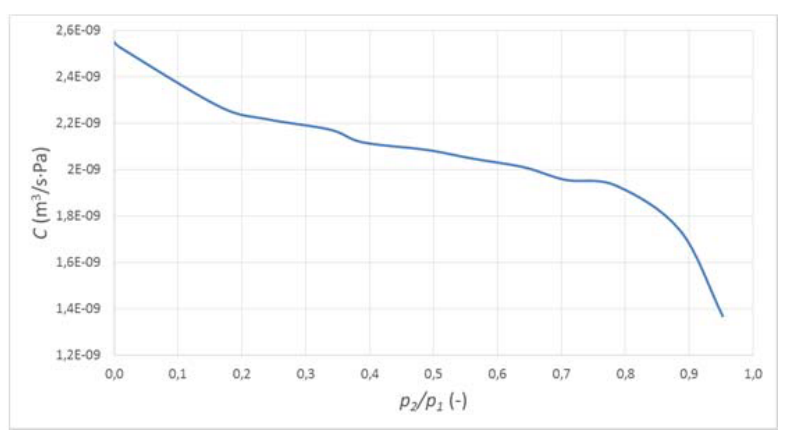

Fig. 11. Characteristic $C=f\left(p_{2} / p_{I}\right)$ of P8 385RF-NG-SPN61-B pilot.

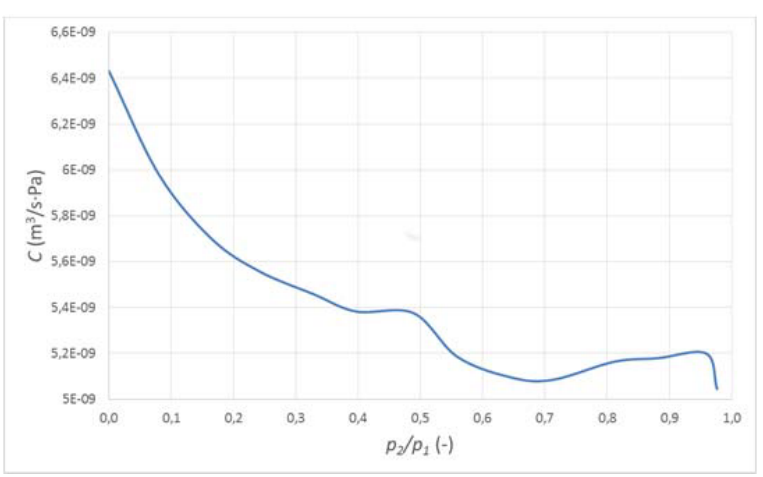

Fig. 12. Characteristic $C=f\left(p_{2} / p_{1}\right)$ of P20 381RF-NG-CPN pilot.

On the basis of formulae (7) and (8), the ratio of critical pressure $b$ under subcritical flow conditions as well as sonic conductance $C$ under choked flow conditions were calculated. The results were average values out of four measurements conducted in accordance with ISO 6358. Table 5 shows the comparison of the experimental research results made on the basis of two methods, and the catalogue data provided by the producer (Table 1 and 2).

Table 5. Comparison of the results.

\begin{tabular}{|c|c|c|c|c|c|c|}
\cline { 2 - 7 } \multicolumn{1}{c|}{} & \multicolumn{2}{c|}{ I method } & \multicolumn{2}{c|}{ II method } & \multicolumn{2}{c|}{$\begin{array}{c}\text { producer's } \\
\text { data }\end{array}$} \\
\cline { 2 - 7 } & $b$ & $C \cdot 10^{-9}$ & $b$ & $C \cdot 10^{-9}$ & $b$ & $C \cdot 10^{-9}$ \\
\hline P8 pilot & 0.338 & 2.17 & 0.283 & 1.91 & 0.34 & 2.08 \\
\hline P20 pilot & 0.329 & 5.46 & 0.342 & 5.19 & 0.33 & 4.42 \\
\hline
\end{tabular}

\section{Summary}

The article presents the methods and the test stand to determine the flow-rate characteristics and parameters of piezo pilot valves. Flow-rate parameters $b$ and $C$ can be calculated on the basis of experimental research with the use of two methods. The selection of the method depends on the possibility to achieve the critical flow rate in the studied component. On the basis of the experimental research conducted, both methods and the data provided by the producer (Table 5) were compared. As it can be seen, the results achieved are quite similar to each other and to the data provided by the producer of the piezo pilots.

\section{References}

1. D. Gapinski, Z. Koruba, I. Krzysztofik, Mech. Syst. Signal. Pr. 45, 2 (2014)

2. Z. Koruba, Z. Dziopa, I. Krzysztofik, J. Theor. Appl. Mec. 48, 1 (2010)

3. I. Krzysztofik, Solid State Phenom. 180 (2012)

4. I. Krzysztofik, Z. Koruba, J. Automat. Inform. Sciences 44, 5 (2012)

5. E. Miko, L. Nowakowski, L. Procedia Eng. 39 (2012a)

6. E. Miko, L. Nowakowski, L. Procedia Eng. 39 (2012b) 
7. L. Nowakowski, M. Miesikowska, M. Blasiak, Edited by Zolotarev I., Radolf V. Proceedings of 22nd International Conference on Engineering Mechanics 2016 (Academy of Sciences of the Czech Republic, 2016)

8. L. Nowakowski, E. Miko, M. Skrzyniarz, Edited by Zolotarev I., Radolf V. Proceedings of 22nd International Conference on Engineering Mechanics 2016 (Academy of Sciences of the Czech Republic, 2016)

9. L. Nowakowski, M. Wijas, Edited by Zolotarev I., Radolf V. Proceedings of 22nd International Conference on Engineering Mechanics 2016 (Academy of Sciences of the Czech Republic, 2016)

10. R. Trochimczuk, M. Gawrysiak, Solid State Phenom. 147-149 (2009)

11. R. Trochimczuk, Solid State Phenom. (2013)

12. R. Trochimczuk, Int. J. Appl. Mec. Eng. 19, 9 (2014a)

13. R. Trochimczuk, T. Kuźmierowski, Int. J. Appl. Mec. Eng. 19, 9 (2014b)

14. D.S. Pietrala, Edited by Zolotarev I., Radolf V. Proceedings of 22nd International Conference on Engineering Mechanics 2016 (Academy of Sciences of the Czech Republic, 2016)

15. J. Zwierzchowski, Edited by Zolotarev I., Radolf V. Proceedings of 22nd International Conference on Engineering Mechanics 2016 (Academy of Sciences of the Czech Republic, 2016)

16. P.A. Laski, J.E. Takosoglu, S. Blasiak, Edited by Fuis V. Proceedings of 20th International Conference on Engineering Mechanics 2014 (Brno University of Technology, Czech Republic, 2014)

17. J.E. Takosoglu, R.F. Dindorf, P.A. Laski, Int. J. Adv. Manuf Tech. 40, 3-4, 2009

18. J.E. Takosoglu, Edited by Zolotarev I., Radolf V. Proceedings of 22nd International Conference on Engineering Mechanics 2016 (Academy of Sciences of the Czech Republic, 2016)

19. J.E. Takosoglu, P.A. Laski, S. Blasiak, G. Bracha, D. Pietrala. Meas. Cont. 49, 2, 2016

20. J.E. Takosoglu, P.A. Laski, S. Blasiak. P. I. Mech. Eng. I-J. Sys. 226, 10, 2012

21. J.E. Takosoglu, P.A. Laski, S. Blasiak, Edited by Fuis V. Proceedings of 20th International Conference on Engineering Mechanics 2014 (Brno University of Technology, Czech Republic, 2014)

22. P.A. Laski, J.E. Takosoglu, S. Blasiak, Robot. Auton. Sys. 72, 2015

23. R. Farana, B. Walek, M. Janosek, J. Zacek, Proceedings of the 15th International Carpathian Control Conference (ICCC), 2014

24. R. Nadolski, K. Ludwinek, Przeglad

Elektrotechniczny, 4, 2012

25. H. Wisniewski, L. Plonecki, Proceedings of the

16th International Carpathian Control Conference

(ICCC), 2015
26. P. Wos, R. Dindorf, Int. J. Dynam. Control, 2014

27. P. Wos, R. Dindorf, Int. J. Appl. Mec. Eng. 17, 3, 2012

28. S. Blasiak, J.E. Takosoglu, P.A. Laski, Edited by Fuis V. Proceedings of 20th International Conference on Engineering Mechanics 2014 (Brno University of Technology, Czech Republic, 2014)

29. P.A. Laski, Edited by Zolotarev I., Radolf V. Proceedings of 22nd International Conference on Engineering Mechanics 2016 (Academy of Sciences of the Czech Republic, 2016)

30. M. Blasiak, R. Kotowski, Przeglad

Elektrotechniczny, 85, 12, 2009

31. M. Blasiak, Edited by Zolotarev I., Radolf V.

Proceedings of 22nd International Conference on

Engineering Mechanics 2016 (Academy of Sciences of the Czech Republic, 2016)

32. D. Janecki, L. Cedro, J. Zwierzchowski, Metrology Meas. Sys. 22, 2, 2015

33. D. Janecki, J. Zwierzchowski, L. Cedro, B. Pol. Acad. Sci-Tech. Sci. 63, 3, 2015

34. I. Krzysztofik, Edited by Zolotarev I., Radolf V. Proceedings of 22nd International Conference on Engineering Mechanics 2016 (Academy of Sciences of the Czech Republic, 2016)

35. Z. Koruba, I. Krzysztofik, P. I. Mech. Eng. K-J. Multi-Body Dyn. 227, K1, 2013

36. G.F. Bracha. Edited by Zolotarev I., Radolf V. Proceedings of 22nd International Conference on Engineering Mechanics 2016 (Academy of Sciences of the Czech Republic, 2016)

37. S. Blasiak, Int. J. of Heat Mass Tran. 81, 2015

38. S. Blasiak, A. Pawinska, Int. J. of Heat Mass Tran, 90, 2015

39. P. Wos, R. Dindorf, Asian J. Contr. 15, 4, 2013

40. P. Wos, R. Dindorf, Mechatronics: Ideas for Industrial Applications, 317, 2015

41. P. Wos, R. Dindorf, Dynamical Systems Applications, 2013

42. ISO 6358. Pneumatic fluid power - Determination of flow-rate characteristics of components using compressible fluids

43. S. Blasiak, J. E. Takosoglu, P. A. Laski, J. Therm. Sci. Techn. 9, 2, 2014

44. S. Blasiak, P. A. Laski, J. E. Takosoglu. Int. J. Heat Mass Tran. 57, 1, 2013

45. I. Krzysztofik, J. Takosoglu, Z. Koruba. Annual Reviews in Control. http://dx.doi.org/10.1016/j.arcontrol.2016.10.003 